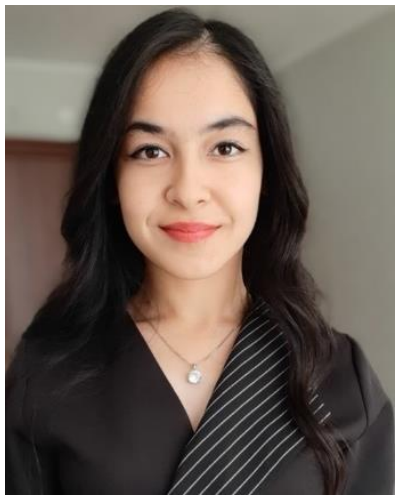

\title{
УСТАНОВЛЕНИЕ СРОКОВ ГОДНОСТИ ЗАМОРОЖЕННЫХ РЫБНЫХ СУПОВ
}

\author{
А.А. Баротова, 2-й курс магистратуры, \\ e-mail: jalili_97@mail.ru \\ ФГБОУ ВО «Калининградский государственный \\ технический университет» \\ И.М. Титова, канд. техн. наук, доц., \\ e-mail: inna.titova@klgtu.ru \\ ФГБОУ ВО «Калининградский государственный \\ технический университет»
}

Статья посвящена исследовательской работе по установлению сроков годности готовых рыбных супов. Приведены результаты физико-химических исследований рыбного бульона - основы для рыбных супов. Выполнены микробиологические исследования сырья и готовых рыбных супов в процессе морозильного хранения при температуре не выше минус $18{ }^{0} \mathrm{C}$ и их органолептическая оценка. Приведены результаты исследований готовых образцов.

Ключевые слова: рыбный суп замороженный, рыбный бульон, сроки годности, готовый рыбный продукт, хранимоспособность рыбной продукиии

\section{ВВЕДЕНИЕ}

Для рыбного кулинарного производства характерен большой, постоянно расширяющийся ассортимент. В то же время объемы выпускаемой кулинарной продукции ограничены, так как большинство ее видов относятся к скоропортящимся.

Основная часть покупателей при выборе пищевых продуктов ориентируется на удобство потребления и предпочитает использовать готовые блюда, не требующие дополнительной обработки. В связи с этим, разработка технологии готовой к употреблению продукции, которую достаточно будет только разогреть, чтобы получить полноценный и вкусный обед, является перспективным направлением в современной пищевой промышленности.

Объект нашего исследования - рыбный суп, изготовленный по технологии с применением комплексного использования пищевых рыбных отходов и компонентов растительного происхождения.

Рыбный суп представляет собой блюдо, приготовленное по общим принципам варки супов, обязательным компонентом которого является рыба, а массовая доля бульона в нем составляет от 20 до 70 \% в зависимости от рецептуры.

Главным преимуществом таких супов считается высокое содержание белков и незаменимых аминокислот, макро- и микроэлементов (кальций, натрий, калий, железо, марганец, магний, фосфор, йод, селен) и витаминов (А, группы В, С, Е, К, РP, Н, бетакаротин).

\section{ЦЕЛЬ И ЗАДАЧИ ИССЛЕДОВАНИЯ}

Целью исследования является установление сроков годности замороженных рыбных супов.

Задачи, поставленные для достижения исследовательской цели: 
- провести микробиологическое исследование сырья и готовой продукции;

- провести физико-химические исследования готовой продукции;

- провести органолептическую оценку готовой продукции в процессе хранения.

\section{МЕТОДЫ И ОБЪЕКТЫ ИССЛЕДОВАНИЯ}

Объектом исследования являлись пищевые отходы от разделки трески и судака, рыбный бульон и готовый рыбный суп.

При проведении исследовательской работы использовали следующие методы: органолептические, физико-химические и микробиологические.

1) Органолептическую оценку качества (внешний вид, цвет, запах и вкус) проводили согласно ГОСТ ISO 6658-2016 «Органолептический анализ» по специально разработанной балльной шкале [1].

2) Прозрачность исследуемых образцов бульона определяли в соответствии с ГОСТ 7636 «Рыба, морские млекопитающие, морские беспозвоночные и продукты их переработки. Методы анализа» [2]. Метод основан на визуальном определении прозрачности в проходящем свете.

3) Определение содержания сухих веществ в исследуемых образцах рыбного бульона осуществляли рефрактометрическим методом согласно ГОСТ 26808 «Консервы из рыбы и морепродуктов. Методы определения сухих веществ» [3].

4) Аминный азот определяли методом формольного титрования по ГОСТ 7636 «Рыба, морские млекопитающие, морские беспозвоночные и продукты их переработки. Методы анализа» [2].

5) Микробиологическая часть исследования включала два этапа:

- Первый заключался в исследовании сырья для производства рыбного супа.

- Второй состоял в проведении исследований готового продукта (рыбного супа) в процессе морозильного хранения и установлении срока годности.

На основании МУК 4.2.1847-04 [4] был составлен график исследования пищевого продукта с предполагаемым сроком хранения продукции 90 сут (табл. 1).

Таблица 1 - График микробиологических исследований образцов замороженного рыбного супа

\begin{tabular}{|c|c|c|c|c|c|}
\hline $\begin{array}{l}\text { Предполагаемый } \\
\text { срок хранения }\end{array}$ & \multicolumn{4}{|c|}{ Периодичность микробиологического контроля } \\
\hline \multirow{2}{*}{90 сут } & $\begin{array}{c}\text { Фон } \\
\text { (свежеприготовленный продукт) }\end{array}$ & $\begin{array}{c}10-\mathrm{e} \\
\text { сутки }\end{array}$ & $\begin{array}{c}20-\mathrm{e} \\
\text { сутки }\end{array}$ & $\begin{array}{c}30-\mathrm{e} \\
\text { сутки }\end{array}$ & $\begin{array}{c}39-\mathrm{e} \\
\text { сутки }\end{array}$ \\
\cline { 2 - 6 } & $54-\mathrm{e}$ сутки & $\begin{array}{c}72-\mathrm{e} \\
\text { сутки }\end{array}$ & $\begin{array}{c}90-\mathrm{e} \\
\text { сутки }\end{array}$ & \multicolumn{2}{|c|}{$\begin{array}{c}\text { сутки } \\
\text { сути }\end{array}$} \\
\hline
\end{tabular}

\section{РЕЗУЛЬТАТЫ ИССЛЕДОВАНИЙ}

Содержание сухих веществ в бульоне, используемом как самостоятельный продукт (кулинарное изделие) или основа для супов, составляет 3,5 \% (Ловачева, 1990). Необходимо подчеркнуть, что такое содержание сухих веществ свойственно для концентрированного костного бульона (из мясного сырья), в то время как сведения для рыбного бульона отсутствуют. Основываясь на вышеизложенных данных, необходимым и достаточным значением содержания сухих веществ в рыбном бульоне принято «не менее 3,4 \%».

В исследовательской работе рыбный бульон выступает в качестве основы для супов (рис. 1).

Для исследования были приготовлены два вида (образца) рыбного супа (рис. 2):

- рыбный суп с оливками; 
- рыбный суп с морепродуктами.
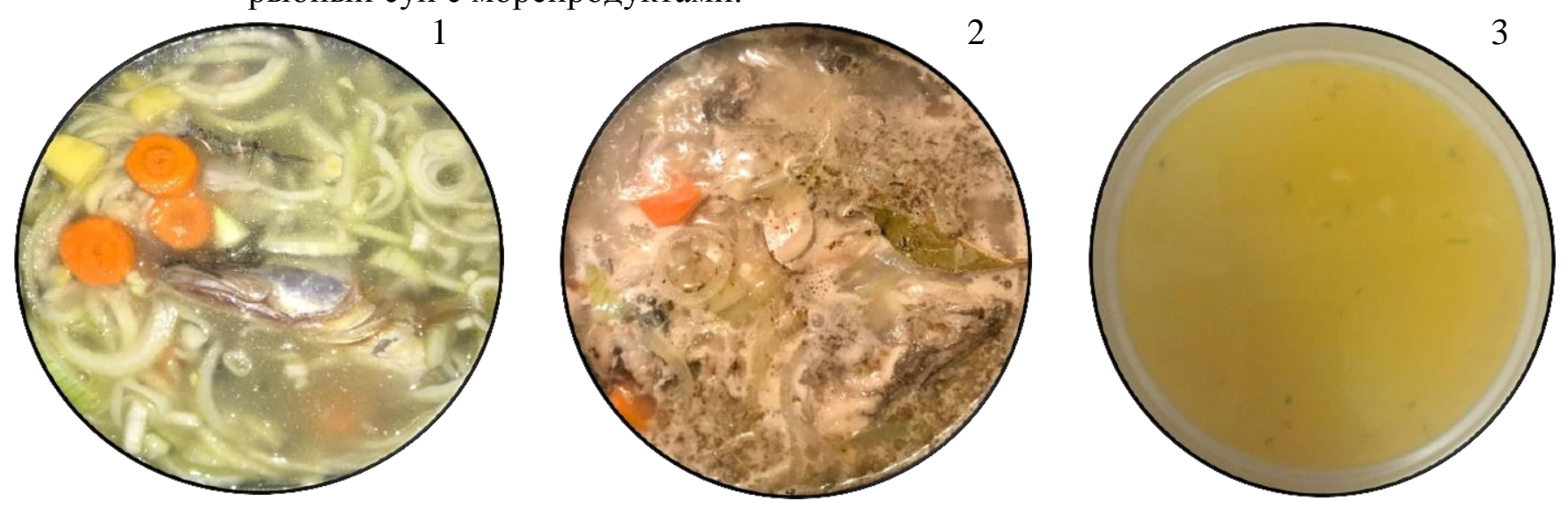

Рис. 1 - Рыбный бульон, 1) и 2) - процесс варки, 3) - после процеживания
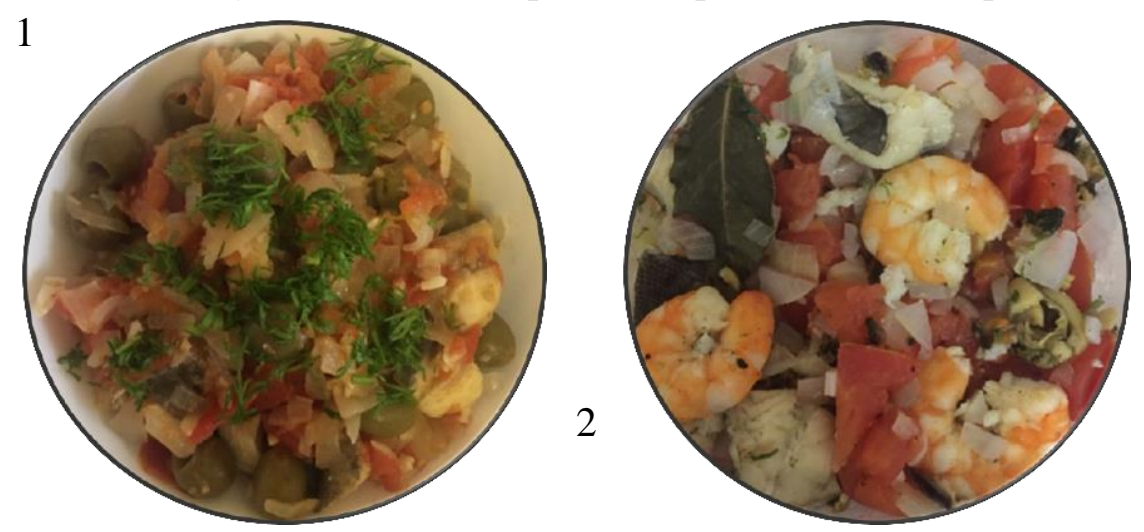

Рис. 2 - Плотная часть рыбного супа: 1) - с оливками; 2) - с морепродуктами

Химический состав и органолептическая оценка рыбного бульона, полученного при термообработке пищевых отходов от разделки судака и трески (головы, хребтовая кость, плавники, кожа) в течение 30; 40 и 50 мин при температуре $100-105^{0}$ С, приведены ниже (табл. 2).

Таблица 2 - Органолептические показатели и химический состав рыбного бульона

\begin{tabular}{|c|c|}
\hline Наименование показателя & Характеристика продукции \\
\hline 1 & 2 \\
\hline \multicolumn{2}{|l|}{30 минут варки: } \\
\hline Внешний вид & Прозрачный \\
\hline Цвет & Светло-жёлтый \\
\hline Запах & Приятный, свойственный рыбному бульону с ароматом специй \\
\hline Вкус & Приятный, без посторонних привкусов \\
\hline Сухие вещества & $5,1 \%$ \\
\hline Аминный азот & $12,74 \mathrm{мг/мл}$ \\
\hline \multicolumn{2}{|l|}{40 минут варки: } \\
\hline Внешний вид & Прозрачный \\
\hline Цвет & Светло-жёлтый \\
\hline Запах & Приятный, свойственный рыбному бульону с ароматом специй \\
\hline Вкус & Приятный, без посторонних привкусов \\
\hline
\end{tabular}


Окончание таблицы

\begin{tabular}{|c|c|}
\hline 1 & 2 \\
\hline Сухие вещества & $6,1 \%$ \\
\hline Аминный азот & 13,16 мг/мл \\
\hline 50 минут варки: & Прозрачный \\
\hline Внешний вид & Светло-жёлтый \\
\hline Цвет & Приятный, без посторонних привкусов \\
\hline Запах & $8,0 \%$ \\
\hline Вкус & 16,8 мг/мл \\
\hline Сухие вещества &
\end{tabular}

Сравнив по органолептическим показателям варианты приготовления бульона, можно отметить, что образцы, которые готовили в течение 40 и 50 мин, отличались более выраженным вкусом. Однако при длительной варке происходит испарении влаги и снижается выход готового продукта. Анализ потерь при приготовлении бульонов, количества сухих веществ и аминного азота позволяет сделать вывод, что с экономической точки зрения без потерь вкуса и существенного снижения пищевой ценности целесообразно варить бульон в течение 40 мин.

Так как пищевой продукт - рыбный суп относится к группе пищевой рыбной продукции, то основными документами, устанавливающими требования к безопасности продукта, являются технические регламенты: ТР ТС 021/2011 [5] и ТР ЕАЭС 040/2016 [6].

Результаты микробиологического исследования используемого сырья (санитарномикробиологических исследований) представлены в табл. 3.

Таблица 3 - Результаты санитарно-микробиологических исследований сырья

\begin{tabular}{|c|c|c|}
\hline Наименование показателя & Нормативные значения & Результаты \\
\hline $\begin{array}{l}\text { Количество мезофильных } \\
\text { аэробных и факультативно- } \\
\text { анаэробных микроорганизмов } \\
\text { (КМАФАнМ) }\end{array}$ & Не более $1 \cdot 10^{5} \mathrm{KOE} / \Gamma$ & $1,8 \cdot 10^{5} \mathrm{KOE} / \Gamma$ \\
\hline $\begin{array}{l}\text { Бактерии группы кишечных } \\
\text { палочек (колиформы) (БГКП) }\end{array}$ & Не допускаются в 0,001 г & Не обнаружены в 0,001 г \\
\hline S. aureus & Не допускаются в 0,01 г & Не обнаружены в 0,01 г \\
\hline V. parahaemolyticus & Не более 100 КОЕ/Гр & Не обнаружены в 25 гр \\
\hline $\begin{array}{l}\text { Патогенные микроорганизмы, в } \\
\text { том числе сальмонеллы }\end{array}$ & Не допускается В 25 Гр & Не обнаружены в 25 гр \\
\hline Listeria monocytogenes & Не допускается В 25 Гр & Не обнаружены в 25 гр \\
\hline
\end{tabular}

По результатам исследований треска мороженая соответствует санитарномикробиологическим критериям по всем показателям, кроме КМАФАнМ. Данный показатель незначительно превысил установленный норматив. Причиной для развития этих групп микроорганизмов могло служить обсеменение из внешней среды (воздуха) во время размораживания сырья. 
Органолептическая оценка и результаты санитарно-микробиологических исследований готовых образцов рыбного супа при морозильном хранении приведены в табл. 4 и 5.

Таблица 4 - Органолептическая оценка готовых образцов при хранении

\begin{tabular}{|c|c|}
\hline Наименование показателя & Характеристика \\
\hline \multicolumn{2}{|l|}{ 1-е сутки: } \\
\hline $\begin{array}{c}\text { Внешний вид } \\
\text { (после оттаивания) }\end{array}$ & $\begin{array}{l}\text { Куски рыбы целые, частичное нарушение целостности отдельных } \\
\text { кусков рыбы. } \\
\text { Овощи, нарезанные в виде кубиков, в основном сохранившие } \\
\text { форму резки }\end{array}$ \\
\hline $\begin{array}{c}\text { Вкус и запах } \\
\text { (после оттаивания) }\end{array}$ & $\begin{array}{l}\text { Приятные, свойственные данному виду продукции с ароматом } \\
\text { пряностей }\end{array}$ \\
\hline $\begin{array}{c}\text { Консистенция } \\
\text { (после оттаивания): } \\
\text { рыбы } \\
\text { овощей } \\
\end{array}$ & $\begin{array}{l}\text { Сочная, не жесткая } \\
\text { Плотная, но не жесткая }\end{array}$ \\
\hline \multicolumn{2}{|l|}{ 10-е сутки: } \\
\hline $\begin{array}{c}\text { Внешний вид } \\
\text { (после оттаивания) }\end{array}$ & $\begin{array}{l}\text { Куски рыбы целые, частичное нарушение целостности отдельных } \\
\text { кусков. } \\
\text { Овощи нарезаны в виде кубиков или брусочков, в основной массе } \\
\text { сохранивших форму резки }\end{array}$ \\
\hline $\begin{array}{c}\text { Вкус и запах } \\
\text { (после оттаивания) }\end{array}$ & $\begin{array}{l}\text { Приятные, свойственные данному виду продукции с ароматом } \\
\text { пряностей }\end{array}$ \\
\hline $\begin{array}{c}\text { Консистенция } \\
\text { (после оттаивания): } \\
\text { рыбы } \\
\text { овощей }\end{array}$ & $\begin{array}{l}\text { Сочная, не жесткая } \\
\text { Плотная, но не жесткая }\end{array}$ \\
\hline \multicolumn{2}{|l|}{ 20-е, 30-е сутки: } \\
\hline $\begin{array}{c}\text { Внешний вид } \\
\text { (после оттаивания) }\end{array}$ & $\begin{array}{l}\text { Куски рыбы целые, частичное нарушение целостности отдельных } \\
\text { кусков. } \\
\text { Овощи нарезаны в виде кубиков или брусочков, в основной массе } \\
\text { сохранивших форму резки }\end{array}$ \\
\hline $\begin{array}{c}\text { Вкус и запах } \\
\text { (после оттаивания) }\end{array}$ & $\begin{array}{l}\text { Приятные, свойственные данному виду продукции с ароматом } \\
\text { пряностей }\end{array}$ \\
\hline $\begin{array}{c}\text { Консистенция } \\
\text { (после оттаивания): } \\
\text { рыбы } \\
\text { овощей }\end{array}$ & $\begin{array}{l}\text { Сочная, не жесткая } \\
\text { Плотная, но не жесткая }\end{array}$ \\
\hline
\end{tabular}

Таблица 5 - Результаты санитарно-микробиологических исследований готовых образцов рыбного супа при морозильном хранении

\begin{tabular}{|c|c|c|}
\hline Наименование показателя & $\begin{array}{c}\text { Нормативные } \\
\text { значения }\end{array}$ & $\begin{array}{l}\text { Результаты } \\
\text { (сутки) }\end{array}$ \\
\hline 1 & 2 & 3 \\
\hline $\begin{array}{l}\text { Патогенные микроорганизмы, в } \\
\text { том числе сальмонеллы }\end{array}$ & $\begin{array}{l}\text { Не допускается } \\
\text { в } 25 \text { гр }\end{array}$ & Не обнаружены в 25 гр \\
\hline Listeria monocytogenes & $\begin{array}{l}\text { Не допускается } \\
\text { в } 25 \text { гр }\end{array}$ & Не обнаружены в 25 гр \\
\hline $\begin{array}{l}\text { Количество мезофильных } \\
\text { аэробных и факультативно- } \\
\text { анаэробных микроорганизмов } \\
\text { (КМАФАнМ) }\end{array}$ & $\begin{array}{c}\text { Не более } 5 \cdot 10^{5} \\
\text { КОЕ/гр }\end{array}$ & $\begin{array}{l}\text { 1-е сутки: } 6,4 \cdot 10^{2} \text { КОЕ/гр (образцы № } 1,2 \text { ) } \\
\text { 10-е сутки: } 1,3 \cdot 10^{3} \text { (№1); } 1,1 \cdot 10^{3} \text { (№2) КОЕ/гр } \\
\text { 20-е сутки: менее } 10 \text { КОЕ/гр (образцы № } 1,2 \text { ) } \\
\text { 30-е сутки: } 1,1 \cdot 10^{4} \text { (№1); } 5,3 \cdot 10^{3} \text { (№2) КОЕ/гр }\end{array}$ \\
\hline
\end{tabular}


Окончание таблицы

\begin{tabular}{|l|c|c|}
\hline \multicolumn{1}{|c|}{1} & 2 & 3 \\
\hline $\begin{array}{l}\text { Бактерии группы кишечных } \\
\text { палочек (колиформы) (БГКП) }\end{array}$ & $\begin{array}{c}\text { Не допускаются } \\
\text { в 0,01 гр }\end{array}$ & Не обнаружены в 0,01 гр \\
\hline S. aureus & $\begin{array}{c}\text { Не допускается } \\
\text { в } 1 \text { гр }\end{array}$ & Не обнаружены в 1 гр \\
\hline Бактерии рода Enterococcus & $\begin{array}{c}\text { Не допускается } \\
\text { в 0,001 гр }\end{array}$ & Не обнаружены в 0,001 гр \\
\hline $\begin{array}{l}\text { Сульфитредуцирующие } \\
\text { клостридии }\end{array}$ & $\begin{array}{c}\text { Не допускается } \\
\text { в 0,1 гр }\end{array}$ & Не обнаружены в 0,1 гр \\
\hline
\end{tabular}

По результатам санитарно-микробиологических исследований готовые образцы рыбного супа соответствуют санитарно-микробиологическим критериям безопасности.

\section{ЗАКЛЮЧЕНИЕ}

Основными показателями качества исследуемого рыбного бульона, выступающего в качестве основы для рыбного супа, определены следующие: содержание сухих веществ, содержание аминного азота и органолептические показатели качества.

Проведены физико-химические исследования готовых образцов рыбного супа, установлено, что наиболее целесообразное время приготовления бульона 40 мин.

Составлен график микробиологического исследования пищевого продукта на основании МУК 4.2.1847-04. Предполагаемый срок хранения продукции 90 сут (при морозильном хранении).

Проведена часть микробиологических исследований рыбных супов (30 сут). По результатам микробиологических анализов на установление сроков годности можно сделать вывод о соответствии продукта - рыбных супов регламентированным микробиологическим критериям безопасности.

Предполагается установить срок годности готовых продуктов - рыбных супов в течение 3 мес. при температуре хранения не выше минус $18{ }^{\circ} \mathrm{C}$.

\section{СПИСОК ЛИТЕРАТУРЫ}

1. ГОСТ ISO 13299-2015 «Органолептический анализ. Методология. Общее руководство по составлению органолептического профиля». [Электронный ресурс]. - Режим доступа: http://docs.cntd.ru/document/1200137276. (дата обращения 16.02.2021).

2. ГОСТ 7636-85 Рыба, морские млекопитающие, морские беспозвоночные и продукты их переработки. Методы анализа (с Изменением N 1). [Электронный ресурс]. Режим доступа: http://docs.cntd.ru/document/1200022224 (дата обращения 16.02.2021).

3. ГОСТ 26808 «Консервы из рыбы и морепродуктов. Методы определения сухих веществ». [Электронный ресурс]. - Режим доступа: http://docs.cntd.ru/document/1200022787. (дата обращения 15.03.2021).

4. МУК 4.2.1847-04 Санитарно-эпидемиологическая оценка обоснования сроков годности и условий хранения пищевых продуктов. [Электронный ресурс]. - Режим доступа: docs.cntd.ru/document/1200035982. (дата обращения 16.02.2021).

5. ТР ТС 021/20110 безопасности пищевой продукции. [Электронный ресурс]. Режим доступа: http://docs.cntd.ru/document/902320560. (дата обращения 15.02.2021).

6. ТРЕАЭС 040/2016О безопасности рыбы и рыбной продукции. [Электронный pecypc]. - Режим доступа: http://docs.cntd.ru/document/420394425. (дата обращения 15.02.2021). 


\title{
DETERMINING THE SHELF LIFE OF FROZEN FISH SOUPS
}

\author{
A.A. Barotova, student \\ e-mail: jalili_97@mail.ru \\ Kaliningrad State Technical University \\ I.M. Titova, PhD, Associate Professor \\ e-mail: inna.titova@klgtu.ru \\ Kaliningrad State Technical University
}

The article is devoted to the research work on the establishment of shelf life of ready-made fish soups. The results of physico-chemical studies of fish broth - the basis for fish soups. Microbiological studies of raw materials and finished fish soups in the process of freezing storage at a temperature not higher than minus $180 \mathrm{C}$ and their organoleptic evaluation were performed. The results of studies of finished samples are presented.

Keywords: frozen fish soup, fish broth, shelf life, finished fish product, storage capacity of fish products 